Short communication

\title{
Use of tilapia, Oreochromis mossambicus, for the control of mosquito breeding in water storage tanks in the Jaffna district of Sri Lanka
}

\author{
Sinnathamby Noble Surendran ${ }^{1, *}$, Arunasalam Kajatheepan ${ }^{1}$, \\ Pavilupillai Justin Jude ${ }^{1}$ and Ranjan Ramasamy ${ }^{2}$ \\ Received 12 September, 2007 Accepted 21 February, 2008 Published online 2 June, 2008
}

\begin{abstract}
Mosquito-borne diseases such as dengue, chikungunya and malaria are of public health importance in Jaffna district. The use of larvivorous fish is perceived as an environmentally sound measure to control mosquitoes. A pilot study in the laboratory and field using Oreochromis mossambicus was carried out to evaluate its potentiality to control Aedes and Anopheles larvae. In the laboratory studies, O. mossambicus showed a greater feeding affinity for Aedes than either Anopheles or artificial fish diet, with a predatory index of 239.7 for Aedes, the fish having $2.9 \mathrm{~g}$ body weight. In the field trial, the introduction of $O$. mossambicus into water storage tanks proved to be effective in eliminating Aedes larvae within 3 days.
\end{abstract}

Key words: Aedes aegypti, Anopheles subpictus, Jaffna, larvivorous fish, mosquito control, Oreochromis mossambicus, Sri Lanka, water storage tanks

\section{INTRODUCTION}

Chikungunya, dengue and malaria are serious health problems in Jaffna, a district located in the dry zone of northern Sri Lanka. The ongoing civil war has severely curtailed mosquito control measures in Jaffna. These are now limited to irregular and infrequent use of one or more of the following - indoor residual spraying against Anopheles vectors of malaria, fogging to target Aedes mosquitoes and larviciding in endemic localities. In the period from November 2006 to January 2007, the Jaffna district, having an estimated population of 0.3 million, experienced an epidemic of chikungunya where more than 11,000 individuals were treated in Government Hospitals (personal communication from the Office of the Deputy Provincial Director for Health Services). Since many persons in Jaffna seek treatment in private clinics, the incidence of chikungunya is likely to be higher. The outbreak highlights the need for more effective mosquito control measures in Jaffna. Aedes aegypti and Ae. albopictus, the potential vectors of dengue and chikungunya, are present throughout the year in populated areas of Jaffna. Human-made habitats constitute the main breeding sites for Aedes mosquitoes. The Aedes breeding sources are domestic storage tanks found in most houses in Jaffna as well as water accumulated in small containers and drains [1]. In addition, the frequent interruption to the electricity supply in Jaffna due to the civil war has compelled many rice mills to install diesel generators with attendant water cooling systems. Water storage tanks for this purpose are placed close to rice mills. Such water storage tanks are often poorly maintained and become breeding sources for Aedes and Anopheles mosquitoes.

Introducing larvivorous fish to eliminate mosquito larvae is considered to be an environmentally friendly method of control [2-4]. Aedes larvae breeding in water storage tanks are reported to be controlled using larvivorous fish in Mexico [2]. We performed a pilot laboratory and field study to evaluate the potential of a larvivorous fish, Oreochromis mossambicus (tilapia), to eliminate Aedes and Anopheles larvae from water storage tanks in Jaffna.

\section{MATERIALS AND METHODS}

\section{Laboratory experiments}

\section{(i) Feeding preference}

Laboratory experiments were carried out to determine the comparative feeding preference of $O$. mossambicus on 3rd and 4th instar larvae of laboratory reared Ae. aegypti

\footnotetext{
' Department of Zoology, Faculty of Science, University of Jaffna, Jaffna, Sri Lanka,

${ }^{2}$ Institute of Medicine, University of Brunei Darussalam, Gadong, Brunei Darussalam

* Corresponding author:

Department of Zoology, Faculty of Science, University of Jaffna, Jaffna 40000, Sri Lanka.

E-mail: noble@jfn.ac.lk
} 
and Anopheles subpictus. Oreochromis mossambicus species with a body length of $6.0-7.5 \mathrm{~cm}$ were collected from domestic wells and were maintained in the aquarium of the Department of Zoology, University of Jaffna. For experiments, selected fish were kept in separate glass tanks containing $2.5 \mathrm{~L}$ of dechlorinated water to acclimatize them to laboratory conditions $\left(29 \pm 22^{\circ} \mathrm{C}\right.$ and natural day-night) for $24 \mathrm{~h}$ before commencing experimentation. They were also not fed overnight before experiments. Ten 3rd and 4th instar Ae. aegypti and An. subpictus larvae apiece were introduced simultaneously into the tanks and the remaining larvae were counted after $5 \mathrm{~min}, 10 \mathrm{~min}, 20 \mathrm{~min}, 30 \mathrm{~min}, 1 \mathrm{~h}$ and $24 \mathrm{~h}$. The experiment was conducted in 3 replicates. Two similar experiments were carried out to determine the feeding preference of $O$. mossambicus on 3rd and 4th instar larvae of both Ae. aegypti and An. subpictus and commercially available fish pellets (New Lion ${ }^{\circledR}$, Thailand). In each experiment, 10 larvae and 10 fish pellets $(\approx 0.8 \mathrm{mg} /$ pellet $)$ were introduced initially. Statistical analysis using Student's $t$-test was performed to determine feeding preference at different time points.

\section{(ii) Predatory index}

In a separate experiment under the same laboratory conditions, a single $O$. mossambicus with a body length of $6.2 \mathrm{~cm}$ was used to determine the predatory index for Aedes larvae. The predatory index was determined as the number of larvae consumed by the fish per gram body weight per day [5]. A sufficient number of 3rd and 4th instar field collected Aedes larvae were released into the same kind of container under the same laboratory conditions. The number of larvae consumed by the fish per day was calculated and the experiment was continued for 3 days.

\section{Field trial}

A field trial was carried out during the dry season from April to May 2007. Five water storage tanks with 15-20 L capacity were selected in Chunnakam town (9.44 N: 80.18 E), where 2031 individuals were treated in the Government Dispensary for suspected CHIK infection from November to December 2006. These tanks, which contain clear water with a few fallen leaves and other debris, were situated within $500 \mathrm{~m}$ of two rice mills and contained 8-10 L of water. One tank was selected as a control and the rest for experimentation. Two $O$. mossambicus ranging from 6.5 to $7.5 \mathrm{~cm}$ in body length were introduced into each experimental tank. Aedes (3rd and 4th instars, and pupae) densities were determined as averages of 5 dips per tank using a $250 \mathrm{ml}$ capacity dipper at $0 \mathrm{~d}, 1 \mathrm{~d}, 3 \mathrm{~d}, 7 \mathrm{~d}, 14 \mathrm{~d}, 21 \mathrm{~d}$ and $28 \mathrm{~d}$ intervals. The percentage reduction in density was calculated using Mulla's formula as cited by Chand and Yadav
[6] giving due weightage to densities in the control tank.

\section{RESULTS}

The results of the comparative feeding preference experiments are shown in Table 1. Oreochromis mossambicus exhibited a significantly greater feeding preference for $A e$. aegypti larvae that for either An. subpictus or artificial fish diet. However the feeding tendency, in terms of time interval, was observed to be slightly different when An. subpictus and fish pellets were provided in combination. This may be due to the fact that they were confined mainly to the surface of the water. The feeding capacity results showed that a $6.2 \mathrm{~cm}$ length $O$. mossambicus can consume $695 \mathrm{Ae}$. aegypti larvae per day (Table 2). The predatory index of the single species for Aedes larvae was found to be 239.7 .

The results of the field experiments are given in Table 3. On average, a $49 \%$ larval reduction was achieved in the experimental tanks after a single day and complete elimination in less than 3 days in all experimental tanks. Even the presence of larvae could not be confirmed visually in the experimental tanks.

\section{DISCUSSION}

The laboratory investigations showed that $O$. mossambicus preferred to feed on Ae. aegypti larvae than on $A n$. subpictus larvae. The significant preference for larval feeding over an artificial fish diet is an indication of the high carnivorocity of $O$. mossambicus. Yadav et al [5] reported a predatory index of 475.6 and 188.5 for a $0.75 \mathrm{~g}(3.5 \mathrm{~cm}$ body length) $O$. mossambicus feeding on Anopheles and Culex larvae respectively (the study was not confined to species level) and further suggested that smaller fish are suitable for mosquito control. However, Chand and Yadav [6] reported that the average consumption of 3rd and 4th instar larvae of Culex quiquefasciatus by a $6.0 \mathrm{~cm}$ length $O$. mossambicus was 656.2 and further observed that the rate of larval consumption increased with body length. The present study shows that a similar size $O$. mossambicus can consume 695 Aedes aegypti larvae per day with a predatory index of 239.7 .

The characteristics of a good larvivorous fish are: a carnivorous nature; voracious surface feeding; tolerance for temperature, $\mathrm{pH}$ fluctuations and common pollutants; resilience to transportation and handling; low demand for human consumption; and high breeding potential [5, 7, 8]. Oreochromis mossambicus is reported to be able to withstand transportation and pollution [6] and to have voracious mosquito larval feeding ability and high breeding potential $[5-7,9]$. 
Table 1. Feeding preference of Oreochromis mossambicus in the laboratory

\begin{tabular}{|c|c|c|c|c|}
\hline \multirow[b]{2}{*}{ Experiment 1} & Time & \multicolumn{2}{|c|}{ Accumulative predation } & \multirow{8}{*}{$\mathrm{t}=9.9, \mathrm{P}<0.01$} \\
\hline & & Ae. Aegypti & An. subpictus & \\
\hline & $5 \mathrm{~min}$ & $10 \pm 0$ & $5.6 \pm 0.58$ & \\
\hline & $10 \mathrm{~min}$ & & $6.3 \pm 0.58$ & \\
\hline & $20 \mathrm{~min}$ & & $7 \pm 1$ & \\
\hline & $30 \mathrm{~min}$ & & $9 \pm 1$ & \\
\hline & $1 \mathrm{~h}$ & & $10 \pm 0$ & \\
\hline & $24 \mathrm{~h}$ & & & \\
\hline \multirow[t]{7}{*}{ Experiment 2} & & Ae. Aegypti & Fish pellets & \multirow{7}{*}{$\mathrm{t}=22.04, \mathrm{P}<0.01$} \\
\hline & $5 \min$ & $10 \pm 0$ & $0.3 \pm 0.58$ & \\
\hline & $10 \mathrm{~min}$ & & $1.6 \pm 1.15$ & \\
\hline & $20 \mathrm{~min}$ & & $4.3 \pm 0.58$ & \\
\hline & $30 \mathrm{~min}$ & & $5.3 \pm 0.58$ & \\
\hline & $1 \mathrm{~h}$ & & $9 \pm 1$ & \\
\hline & $24 \mathrm{~h}$ & & $10 \pm 0$ & \\
\hline \multirow[t]{7}{*}{ Experiment 3} & & An. Subpictus & Fish pellets & \\
\hline & $5 \mathrm{~min}$ & $6.6 \pm 0.58$ & $1.3 \pm 1.53$ & $\mathrm{t}=5.3, \mathrm{P}<0.05$ \\
\hline & $10 \mathrm{~min}$ & $7 \pm 0.58$ & $1.6 \pm 1.15$ & $\mathrm{t}=6.7, \mathrm{P}<0.05$ \\
\hline & $20 \min$ & $8 \pm 1$ & $3 \pm 1$ & $\mathrm{t}=6.1, \mathrm{P}<0.05$ \\
\hline & $30 \mathrm{~min}$ & $10 \pm 0$ & $4 \pm 1$ & $\mathrm{t}=10.4, \mathrm{P}<0.01$ \\
\hline & $1 \mathrm{~h}$ & & $7 \pm 1$ & \\
\hline & $24 \mathrm{~h}$ & & $10 \pm 0$ & \\
\hline
\end{tabular}

Table 2. Feeding potential of Oreochromis mossambicus on Aedes aegypti larvae in the laboratory

\begin{tabular}{|c|c|c|c|c|c|c|c|}
\hline \multirow[t]{2}{*}{$\begin{array}{l}\text { Length } \\
(\mathbf{c m})\end{array}$} & \multirow[t]{2}{*}{$\begin{array}{l}\text { Weight of } \\
\text { fish } \\
\text { (g) }\end{array}$} & \multirow[t]{2}{*}{$\begin{array}{l}\text { No of larvae } \\
\text { initially } \\
\text { introduced }\end{array}$} & \multicolumn{3}{|c|}{$\begin{array}{l}\text { Number of } 3 \mathrm{rd} \text { and } 4 \mathrm{th} \\
\text { instars consumed/day }\end{array}$} & \multirow{2}{*}{$\begin{array}{c}\text { Average } \\
\text { number of } \\
\text { larvae } \\
\text { consumed/ } \\
\text { Fish/Day }\end{array}$} & \multirow[t]{2}{*}{$\begin{array}{l}{ }^{*} \text { Predatory } \\
\text { index }\end{array}$} \\
\hline & & & Day 1 & Day 2 & Day 3 & & \\
\hline 6.2 & 2.9 & 1000 & 738 & 728 & 619 & 695 & 239.7 \\
\hline
\end{tabular}

*No. of larvae consumed per gram body weight per day [5]

Table 3. Larvivorous potential of Oreochromis mossambicus in water storage tanks

\begin{tabular}{cccc}
\hline & \multicolumn{2}{c}{$\begin{array}{c}\text { Density of 3rd and 4th instar and pupae } \\
\text { (average of 5 dips) }\end{array}$} & \\
\cline { 2 - 3 } Time in days & \% reduction \\
\cline { 2 - 3 } & Control tank & $\begin{array}{c}\text { Experimental tanks } \\
\text { (average of 4 tanks) }\end{array}$ & \\
\hline 0 & 76.3 & $52.4 \pm 13.6$ & - \\
1 & 74.5 & $27.3 \pm 8.9$ & $49.25 \pm 4.7$ \\
3 & 64.3 & 0 & 100 \\
7 & 47.5 & 0 & 100 \\
14 & 34.6 & 0 & 100 \\
21 & 20.0 & 0 & 100 \\
28 & 30.8 & 0 & 100 \\
\hline
\end{tabular}

Oreochromis mossambicus was introduced into freshwater reservoirs in Sri Lanka from East Africa in 1952 in order to increase inland fish yield [9]. It has now spread throughout the island up to an elevation of $1000 \mathrm{~m}$. Al- though $O$. mossambicus is largely available in freshwater ponds and domestic wells in Jaffna, it is not a popular fish for eating. The widespread occurrence of this species in the Jaffna district also indicates its adaptability to the existing 
environmental conditions and suitability for implementation in mosquito control.

Oreochromis mossambicus was successfully used to control Culex larvae in cow dung pits in India [6]. The feeding capacity of $O$. mossambicus on anopheline larvae has been reported from Sri Lanka [7]. However there are no reports on its potential for controlling Aedes larvae. The present pilot study showed that the introduction of $O$. mossambicus can effectively reduce mosquitoe, especially Aedes aegypti, density in water storage tanks in Jaffna and suggests that this species may help to prevent epidemics caused by mosquito-borne diseases. Large-scale field interventions in Jaffna are warranted by these findings.

\section{ACKNOWLEDGMENTS}

We gratefully acknowledge the laboratory assistance of K Sribandakaran and S Tharmasena of the Department of Zoology, University of Jaffna.

\section{REFERENCES}

1 . Surendran SN, Kajatheepan A, Sanjeefkumar KFA, Jude PA. Seasonality and insecticide susceptibility of dengue vectors: an ovitrap based survey in a residential area of northern Sri Lanka. Southeast Asian J Trop Med Public Health 2007; 38: 276-282.
2 . Marinez-Ibarra JA, Guillen GY, Arredondo-Jimenez JI, Rodrgez-Lopez MH. Indigenous fish species for the control of Aedes aegypti in water storage tanks in Southern Mexico. Bio Control 2002; 47: 481-486.

3 . Yadav RS, Das MK. Role of Danio and Oryzias fishes in the control of mosquito breeding in rice fields. In: Sharma VP, Apurba Ghosh, editors. Larvivorous fish of inland ecosystems. Malaria Research Centre, Delhi. 1994; p. 61-68.

4 . Dua VK, Sharma SK. Use of guppy and Gambusis fishes for control of mosquito breeding at BHEL industrial complex, Hardwar (UP). In: Sharma VP, Apurba Ghosh, editors. Larvivorous fish of inland ecosystems. Malaria Research Centre, Delhi. 1994; p. 35-46.

5 . Yadav RS, Padhan K, Sharma VP. Fishes of district Sundargarh, Orissa, with special reference to their potential in mosquito control. Indian J Malariol 1992; 29: 225-233.

6 . Chand SK, Yadav RS. Use of Oreochromis mossambicus (Peters) in controlling mosquito breeding in cow dung pits. In: Sharma VP, Apurba Ghosh, editors. Larvivorous fish of inland ecosystems. Malaria Research Centre, Delhi. 1994; p. 115-120.

7 . Kusumawathie PHD, Wickremasinghe AR, Karunaweera ND, Wijeyaratne MJS. Larvivorous potential of fish species found in river beds pool below the major dams in Sri Lanka. J Med Entomol 2006; 43(1): 79-82.

8 . Wickramasinghe MB, Costa $\mathrm{HH}$. Mosquito control with larvivorous fish. Parasitology Today 1986; 2; 228-230.

9 . Food and Agriculture Organization of the United Nations (http://www.fao.org/docrep/006/P6757E/P6757E17.htm) 